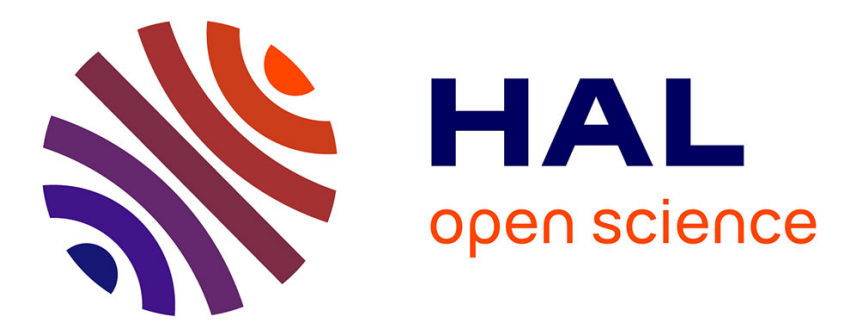

\title{
Microwave frequency behavior of the EPR copper(II) ion pairs spectrum formed in the $\mathrm{CuCe}$ oxide
}

Antoine Aboukais, Abdelrhani Bennani, Cossi Faustin Aissi, Michel Guelton, Jacques C. Vedrine

\section{To cite this version:}

Antoine Aboukais, Abdelrhani Bennani, Cossi Faustin Aissi, Michel Guelton, Jacques C. Vedrine. Microwave frequency behavior of the EPR copper(II) ion pairs spectrum formed in the CuCe oxide. Chemistry of Materials, 1992, 4, pp.977-979. 10.1021/cm00023a008 . hal-00006212

\section{HAL Id: hal-00006212}

\section{https://hal.science/hal-00006212}

Submitted on 8 Nov 2021

HAL is a multi-disciplinary open access archive for the deposit and dissemination of scientific research documents, whether they are published or not. The documents may come from teaching and research institutions in France or abroad, or from public or private research centers.
L'archive ouverte pluridisciplinaire HAL, est destinée au dépôt et à la diffusion de documents scientifiques de niveau recherche, publiés ou non, émanant des établissements d'enseignement et de recherche français ou étrangers, des laboratoires publics ou privés. 


\section{Microwave Frequency Behavior of the EPR Copper(II) Ion Pairs Spectrum Formed in CuCe Oxide}

Antoine Aboukaïs,* Abdelrhani Bennani, Cossi Faustin Aissi, Michel Guelton, and Jacques C. Vedrine ${ }^{\dagger}$

Laboratoire de Catalyse Hétêrogène URA CNRS 402

Université des Sciences et Technologies de Lille I 59655 Villeneuve d'Ascq Cedex, France

In previous work, ${ }^{1-3}$ it has been shown, mainly by EPR, that copper-cerium oxides $(\mathrm{Cu} / \mathrm{Ce}=0.01)$ contain $\mathrm{Cu}^{2+}$ ion pairs. Well-resolved EPR spectra of copper(II) ion pairs have been evidenced at either X-band $(9.3 \mathrm{GHz})$ or $\mathrm{Q}$-band $(35 \mathrm{GHz})$ frequencies. The hyperfine structure of the half-field signal $\left(\Delta m_{\mathrm{s}}=2\right)$ and the parallel and the perpendicular components of the normal-field signal $\left(\Delta m_{\mathrm{s}}\right.$ $=1$ ) have been observed. Since the EPR spectra of dimers have been seldom studied at $\mathrm{Q}$-band frequency, the purpose of this work is to show some anomalous behavior of a copper(II) ion pairs spectrum with the variation of the microwave frequency of the spectrometer.

The $\mathrm{CuCe}$ Oxide sample with an atomic ratio $\mathrm{Cu} / \mathrm{Ce}=$ 0.01 was prepared by calcination of the coprecipitated hydroxides of cerium and copper at $1173 \mathrm{~K}$ for $3 \mathrm{~h}$ under a flow of dry air.

The EPR spectra were obtained with a Varian (V-4502) spectrometer using the $\mathrm{X}$ and $\mathrm{Q}$ bands as microwave frequencies. The spectra were recorded at 77 and $293 \mathrm{~K}$. The $g$ values were measured in comparison with DPPH ( $g=$ 2.0036) or directly by measuring the magnetic field $\mathrm{H}$ and the microwave frequency $\nu$.

The EPR spectra of $\mathrm{CuCe}$ oxide $(\mathrm{Cu} / \mathrm{Ce}=0.01)$ recorded at X-and Q-band frequencies are shown in Figure 1. As it was indicated elsewhere,$^{1-3}$ these well-resolved spectra clearly demonstrate the existence of three signals:

One signal, $\mathrm{K}$, corresponds to copper(II) ion pairs. In fact, the seven components with relative intensities $1: 2: 3: 4: 3: 2: 1$ of the hyperfine splitting with two identical nuclei $\mathrm{Cu}^{2+}$ of $\operatorname{spin}{ }^{3} / 2$ observed for $g_{\|}$and $g_{\perp}$ and the weak

\footnotetext{
'Institut de Recherche sur la Catalyse, CNRS, 2 Avenue Albert Einstein, 69626 Villeurbanne, France

(1) Aboukais, A.; Guelton, M.; Vedrine, J. C. C. R. Acad. Sci. Paris 1991, $t 313$ (Sêrie 2), 169.

(2) Aboukais, A.; Bennani, A.; Aissi, C. F.; Wrobel, G.; Guelton, M.; Vedrine, J. C. J. Chem. Soc., Faraday Trans 1992, 88, 615.

(3) Aboukais, A.; Bennani, A.; Aissi, C. F.; Wrobel, G.; Guelton, M. J. Chem. Soc., Faraday Trans. 1992, 88, 1321.
} 

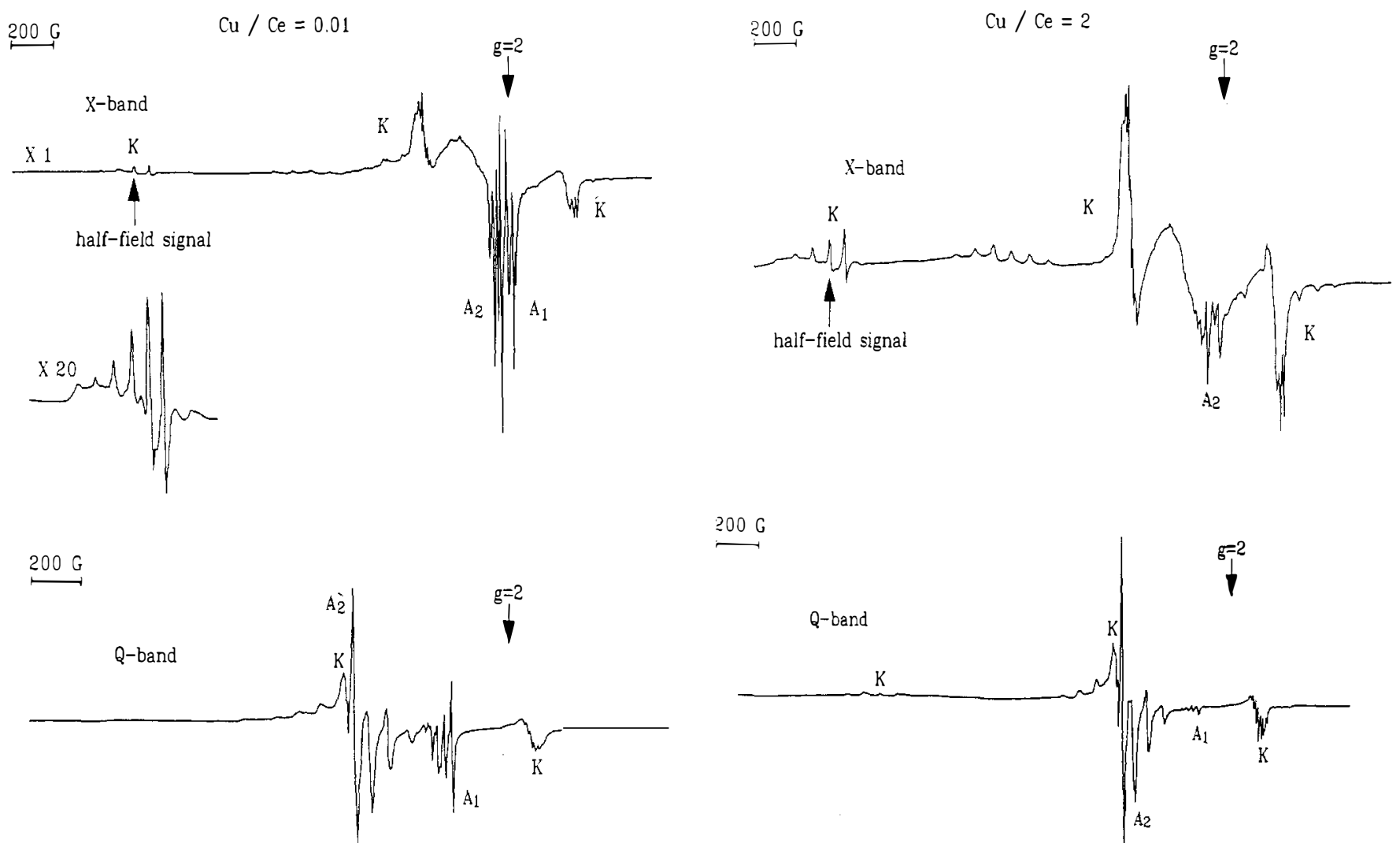

Figure 1. X-and Q-band EPR spectra of $\mathrm{CuCe}$ oxide $(\mathrm{Cu} / \mathrm{Ce}$ $=0.01)$ recorded at $77 \mathrm{~K}$.

signal obtained at half the normal magnetic field intensity, are characteristic of the existence of copper(II) ion pairs. From the intensities ratio measured by double integration of the signals observed at $\Delta m_{\mathrm{s}}=2$ and $\Delta m_{\mathrm{s}}=1$, the interion distance between the two $\mathrm{Cu}^{2+}$ ions, forming the pair, has been evaluated as $3.4 \AA$. From the separation of perpendicular and parallel components, directly deduced from spectra of the Figure 1, the zero-field constant $D$ has been found to be equal to $0.066 \mathrm{~cm}^{-1}$. The splitting between the singlet- and the triplet-state $J$ has been also calculated either from the dipolar and pseudodipolar interaction or from the Boltzmann distribution and the Curie law. The value deduced $\left(J=52.5 \mathrm{~cm}^{-1}\right)$ was much larger than $A_{\text {iso }}\left(0.0037 \mathrm{~cm}^{-1}\right)$ of the $\mathrm{K}$ signal.

Two signals, $A_{1}$ and $A_{2}$, correspond to isolated monomeric $\mathrm{Cu}^{2+}$ ions in $\mathrm{CeO}_{2}$. The first one has been correlated with copper(II) species in octahedral sites with a tetragonal distorsion. From EPR parameters, it has been shown that these $\mathrm{Cu}^{2+}$ monomeric ions $\left(\mathrm{A}_{1}\right)$ are the precursors of the copper(II) ion pairs in ceria. The other one ( $\mathrm{A}_{2}$ signal) has been attributed to $\mathrm{Cu}^{2+}$ ions localized in surface substitutional sites with a square-pyramidal symmetry.

We have also noticed previously ${ }^{2}$ that the $A_{2}$ signal has been obtained at both X-and Q-band frequencies, whereas the half-field signal has been observed only in the X-band spectrum (Figure 1).

When a CuCe oxide sample with an atomic ratio $\mathrm{Cu} / \mathrm{Ce}$ $=2$ was prepared and calcined at $1173 \mathrm{~K}$ as indicated previously, the X-band EPR spectrum is mainly formed of the $\mathrm{K}$ and $\mathrm{A}_{2}$ signals, and apparently no trace of the $A_{1}$ signal is observed (Figure 2a). Contrary to that observed in $\mathrm{CuCe}$ oxide $(\mathrm{Cu} / \mathrm{Ce}=0.01) \mathrm{X}$-band spectrum, the relative intensity of the $A_{2}$ signal is weaker than $K$ dimer signal. When the Q-band spectrum of this solid is recorded (Figure 2b), the intensity of the $A_{2}$ signal becomes larger than $K$ and the $A_{1}$ signal is observed with a weak intensity.

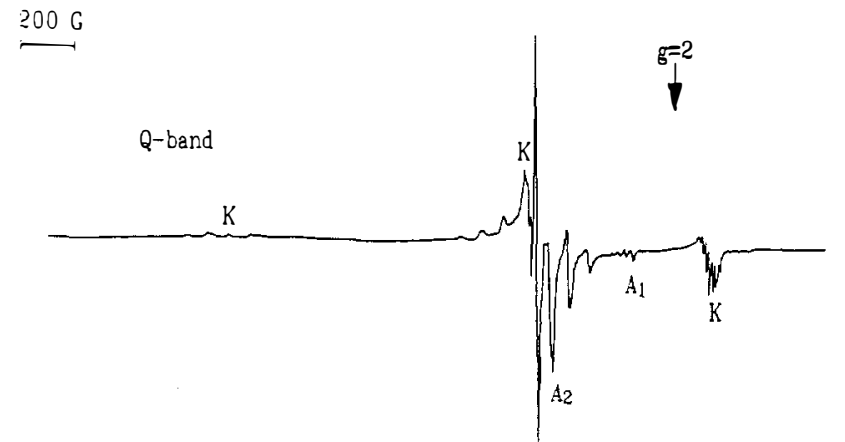

Figure 2. $\mathrm{X}$ and $\mathrm{Q}$ band $\mathrm{EPR}$ spectra of $\mathrm{CuCe}$ oxide $(\mathrm{Cu} / \mathrm{Ce}$ $=2$ ) recorded at $77 \mathrm{~K}$.

From these results it is obvious to deduce that the $A_{2}(Q)$ signal, obtained at $Q$ band, must not correspond to $A_{2}(X)$ signal, obtained at $\mathrm{X}$ band, as was indicated previously ${ }^{2}$ in the case of $\mathrm{Cu} / \mathrm{Ce}=0.01$. To confirm this it has been demonstrated that the EPR parameters of $\mathrm{A}_{2}(\mathrm{X})$ and $A_{2}(Q)$ are different, since the separation between $A_{1}$ and $A_{2}(Q)$ is greater in comparison with that of $A_{1}$ and $A_{2}(X)$ when the $X$ band is replaced by the $Q$ band. Since no signal in the X-band spectrum has the same shape and the same splitting constant as that of the $A_{2}(Q)$ signal, we are then allowed to wonder about the origin of this signal and what happened to the $A_{2}(X)$ signal in the $Q$ band spectrum.

The direct comparison of EPR signal obtained in the $\mathrm{X}$ - and $\mathrm{Q}$-band spectra allows us to notice that the halffield signal observed at the $\mathrm{X}$ band is the only one in the spectrum which can be considered as similar in shape and splitting constant $(80 \mathrm{G})$ to that of the $A_{2}(Q)$ signal. Are we then allowed to suppose that the $A_{2}(Q)$ signal is the half-field signal of the $\mathrm{Q}$-band spectrum? To answer this question, it is necessary to have recourse to some theoretical considerations and to the literature of the dimeric spectra.

It has been shown ${ }^{4}$ that if the zero-field splittng $D$ of a dimer is larger than $h \nu$, where $\nu$ is the microwave frequency of the spectrometer, it may be impossible to observe an EPR spectrum or only some of the allowed transitions may be observed. On the contrary, if $D$ is less than $h \nu$, the resulting EPR spectrum $\left(\Delta m_{\mathrm{s}}=1\right.$ and $\Delta m_{\mathrm{s}}$ $=2$ ) shows considerably anisotropy. Since the zero-field splitting D previously calculated from EPR parameters of the copper(II) ion pairs signal (K) of CuCe oxide $(D=$ $\left.0.066 \mathrm{~cm}^{-1}\right)^{2}$ is less than the $\mathrm{X}$-band frequency $\left(0.3 \mathrm{~cm}^{-1}\right)$ and the $\mathrm{Q}$-band frequency $\left(1.1 \mathrm{~cm}^{-1}\right)$, the allowed and the

(4) Smith, T. D.; Pilbrow, J. R. Coord. Chem. Rev. 1974, 13, 173. 
forbidden transitions ought to be observed in the $\mathrm{K}$ signal and $\mathrm{X}$ - and Q-band spectra.

On the other side, it has been demonstrated ${ }^{5}$ that the position of the low-field edge of the half-field signal in a powder spectrum is given by

$$
H_{\min }\left(\Delta m_{\mathrm{s}}=2\right)=\frac{1}{2 g \beta}\left[(h \nu)^{2}-4\left(\frac{D^{2}}{3}+E^{2}\right)\right]^{1 / 2}
$$

where $\nu$ is the spectrometer operating frequency and $D$ and $E$ are the zero-field splitting parameters. For axial symmetry, $E=0$.

From eq 1 , it is then possible to determine the $H_{\min }$ position of the half-field signal when the X-band frequency is replaced by the $\mathrm{Q}$ band. The value obtained $(H=5813$ $\mathrm{G}$ ) is shifted more than $250 \mathrm{G}$ to a higher field from that directly obtained ( $H=5558 \mathrm{G}$ ) by the usual equation of Zeeman effect $(h \nu=g \beta H)$. Despite this shift, the value obtained corresponds to a magnetic field already recorded by $Q$ band. Since no EPR signal has been observed, it is then possible to suppose that the intensity of this signal can be very weak. In fact, the relative intensity $I_{\text {rel }}$ between the signal observed at $\Delta m_{\mathrm{s}}=2$ and that obtained at $\Delta m_{\mathrm{s}}$ $=1$ is given by $^{5}$

$$
I_{\text {relative }}=\frac{I\left(\Delta m_{\mathrm{s}}=2\right)}{I\left(\Delta m_{\mathrm{s}}=1\right)}=\frac{A}{r^{6}}\left(\frac{9.1}{\nu}\right)^{2}
$$

$A$ is a constant $\left(A=(21 \pm 2) \times 10^{-6}\right), r$ is the interion distance, and $\nu$ is the microwave frequency. From eq 2, the $I_{\text {rel }}$ will be decreased approximately 15 times less when the $\mathrm{X}$ band is replaced by the $\mathrm{Q}$ band. But, despite this decrease, the sensitivity of the EPR spectrometer remains able to detect such intensity of signal if this latter exists. Then, no trace of the half-field signal has been evidenced even with the highest gain on the spectrometer. The absence of the half-field signal in the $\mathrm{Q}$-band spectrum, where should it exist, allows us to suppose that a shift has occurred.

To our knowledge, generally, no shift of the half-field signal does occur from the low magnetic field to the high field, when the X-band frequency has been replaced by the $Q$ band. In fact, in the case of CuTh oxide, ${ }^{6,7} a$ dimer and monomers have been evidenced by EPR. One of signals is similar to $\mathrm{A}_{2}(\mathrm{X})$ obtained in CuCe oxide. Despite that the thoria and the ceria have the same crystallographic structure, the $\mathrm{A}_{2}(\mathrm{Q})$ signal was not obtained in $\mathrm{CuTh}$ oxide when the $\mathrm{X}$ band was replaced by the $\mathrm{Q}$ band.

However, in one particular case, a significant case of one low-field signal had been obtained by Jones et al. ${ }^{8}$ in copper acetate monohydrate. Indeed, this latter compound had been widely studied by Bleaney and Bowers. ${ }^{9}$ The EPR spectrum of $\mathrm{Cu}^{2+}$ ion pairs coupled via an antiferromagnetic exchange interaction to form a singlet ground state and a thermally accessible $\left(J=-260 \mathrm{~cm}^{-1}\right)$ triplet state. A signal at low magnetic field had been observed in the X-band EPR spectrum. When the experiment on copper acetate monohydrate was repeated at $Q$-band frequency by Jones et al., the low-field signal significantly shifted to a higher field with a concomitant splitting of the

(5) Eaton, S. S.; More, K. M.; Sawant, B. M.; Eaton, G. R. J. Am. Chem. Soc. 1983, 105, 6560.

(6) Bechara, R.; Wrobel, G.; Aissi, C. F.; Guelton, M.; Bonnelle, J. P.; Aboukais, A. Chem. Mater. 1990, 2, 518.

(7) Bechara, R.; D'Huysser, A.; Aissi, C. F.; Guelton, M.; Bonnelle, J. P.; Aboukais, A. Chem. Mater. 1990, 2, 522

(8) Jones, R.; Janes, R.; Armstrong, R.; Singh, K. K.; Edwards, P. P.; Keeble, D. J.; Harrison, M. R. J. Chem. Soc., Faraday Trans. 1990, 86, 683. 451.

9) Bleaney, B.; Bowers, K. D. Proc. R. Soc. London, Ser. A 1952, 214 lines and significant increase of the signal intensity. But, in that case, the low-field signal observed at X-band frequency, in copper acetate, by Bleaney and Bowers is similar to that obtained from the superconducting oxides below $T_{\mathrm{c}}{ }^{10}$ Therefore, the significant shift of this signal observed by Jones et al. at Q-band frequency has been explained by the superconductivity properties. However, this low-field signal is completely different from the half-field signal of the $\mathrm{CuCe}$ oxide samples, and then it is not allowed to suppose that the half-field signal, observed at the X-band spectrum, can shift with the microwave frequency.

In conclusion, the origin and the nature of the $A_{2}(Q)$ signal remain unresolved, and if we suppose that this signal is different than $\mathrm{A}_{2}(\mathrm{X})$ signal, a particular theoretical work should be necessary to explain that. In addition, measurements have to be made at intermediate frequencies (between $\mathrm{X}$ and $\mathrm{Q}$ bands) and at low temperatures $(4.2 \mathrm{~K}$ ) to follow the behavior of the dimer spectrum and specifically the $\mathrm{A}_{2}(\mathrm{Q})$ signal.

Registry No. $\mathrm{Cu}^{2+}, 15158-11-9$; copper cerium oxide, 1252567-6.

(10) Khachaturyan, K.; Wekber, E. R.; Tejedor, P.; Stacy, A. M.; Portis, A. M. Phys. Rev. 1987, B36, 8309.

\section{$\left[\mathrm{CF}_{3} \mathrm{Au}(\mathrm{C} \equiv \mathrm{NMe})\right]$ as a Precursor for CVD of Gold}

Neil H. Dryden, Joseph G. Shapter, Leighton L. Coatsworth, Peter R. Norton, and Richard J. Puddephatt*

Department of Chemistry
University of Western Ontario
London, Canada N6A $5 B 7$
Received May 19, 1992
Revised Manuscript Received July 27, 1992

Introduction

The high conductivity and stability to corrosion of gold have led to its widespread use in modern electronics and hence to interest in chemical vapor deposition (CVD) of gold.1-5 Established precursors for CVD of gold include organogold(III) complexes such as [AuMe ${ }_{2}$ $\left.\left(\mathrm{CF}_{3} \mathrm{COCHCOCF}\right)_{3}\right]^{1}$ and $\left[\mathrm{AuMe}_{3} \mathrm{~L}\right],^{2-4}$ where $\mathrm{L}=\mathrm{PMe}_{3}$ or $\mathrm{PEt}_{3}$, and organogold(I) complexes such as [AuMeL], ${ }^{2,4,5}$ where $\mathrm{L}=\mathrm{PMe}_{3}, \mathrm{PEt}_{3}$, or MeNC. CVD of gold from these alkylgold(I) complexes can be carried out at low temperature but the compounds have poor thermal and photochemical stability and so are not easily stored. ${ }^{2}$ Since trifluoromethylgold(I) complexes are more stable than the corresponding methylgold(I) complexes, ${ }^{6}$ their use as precursors for CVD of gold has now been investigated.

The new organogold(I) complex $\left[\mathrm{CF}_{3} \mathrm{AuCNMe}\right]$ was prepared according to

(1) (a) Kodas, T. T.; Baum, T. H.; Comita, P. J. Cryst. Growth 1988 87, 378. (b) Baum, T. H. J. Electrochem. Soc. 1987, 134, 2616. (c) Lason C. E.; Baum, T. H.; Jackson, R. L. J. Electrochem. Soc. 1987, 134, 266. (d) Baum, T. H.; Jones, C. R. Appl. Phys. Lett. 1985, 47, 538.

(2) Puddephatt, R. J.; Treurnicht, I. J. Organomet. Chem. 1987, 319, 129.

(3) Aylett, M. R. Chemtronics 1986, 1, 146

Aesselhauser, J.; Flint, E. B.; Suhr, H. Appl. Surf. Sci. 1992, 54,

(5) Jubber, M.; Wilson, J. I. B.; Davidson, J. L.; Fernie, P. A.; John, P. Appl. Phys. Lett. 1989, 55, 1477.

(6) (a) Sanner, R. D.; Satcher, J. H. Jr.; Droeger, M. W. Organometallics 1989, 8, 1498. (b) Morrison, J. A. Adv. Inorg. Chem. Radiochem. 1983, 27, 293. 